\title{
Evaluation of the Effect of the Solubility Model on Antisolvent Crystallization Optimization
}

\author{
D. J. Widenski*, A. Abbas**, J. A. Romagnoli* \\ *Chemical Engineering Department, Louisiana State University, Baton Rouge, LA 70803 \\ USA (e-mail:dwiden1,jose@lsu.edu) \\ **School of Chemical and Biomolecular Engineering, University of Sydney, Sydney, NSW 2006 \\ Australia (e-mail: alia@usyd.edu.au)
}

\begin{abstract}
The use of predictive solubility models can be of great use for crystallization modeling, and can decrease the amount of experimental data needed to create a robust crystallization model. In this paper, predictive solubility models such as MOSCED, UNIFAC, NRTL-SAC, and the Jouyban-Acree model are compared against an empirical model for predicted solubility accuracy. The best models are subsequently compared against the empirical model for the antisolvent crystallization of acetaminophen in acetone using water. Two different optimization objective functions are executed for each solubility model to generate corresponding optimal profiles. The effect of these optimal profiles on the predicted crystal properties is evaluated.
\end{abstract}

Keywords: Optimization, Solubility Model, Crystallization, Antisolvent, NRTL-SAC, Jouyban-Acree, Population Balance

\section{INTRODUCTION}

Crystallization is an important unit operation for the production of pharmaceuticals, fertilizers, and fine chemicals. Optimal crystallization operation often requires a crystallization model. This crystallization model, typically based on population balances (Hulburt and Katz, 1964; Ramkrishna, 1985; Randolph and Larson, 1988), requires a companion solubility model. Empirical solubility models have been extensively used in crystallization modelling (Zhou et al., 2006; Nowee et al., 2008; Lindenberg et al., 2009). It is of interest to understand how other predictive solubility models such as the MOSCED, NRTL-SAC, UNIFAC, and Jouyban-Acree models can be incorporated into crystallization models and how their accuracy of predicting the solubility profiles influences both the crystallization model prediction and optimal profile calculation. The outcome of combining predictive solubility modelling with the crystallization model is expected to reduce the need for solubility experimental data and consequently streamline the optimization of the crystallization process.

The solubility prediction is an important aspect of any crystallization model because its prediction is the basis for any crystallization phenomena. Crystallization is caused by supersaturation which is defined as the difference between the solution concentration and the equilibrium concentration (absolute supersaturation), or the ratio of the solution and equilibrium concentrations (relative supersaturation).

This paper investigates the effect of different solubility models on the optimization of antisolvent crystallization. Both the effect of the model on the predicted optimal profile and on the result of these models' optimal profiles implemented into a validated crystallization model will be evaluated. Specifically, we examine the effect on the supersaturation, mean size, and volume percent crystal size distribution (CSD) profiles. Although there has been extensive work done in the area of crystallization control and optimization (Braatz, 2002; Zhou et al., 2006; Nowee et al., 2008; Sheikhzadeh et al., 2008), as far as we are aware there is no study that has investigated the use of predictive solubility models in developing optimal antisolvent feed profiles.

\section{SOLUBILITY MODELS}

\subsection{MOSCED \& UNIFAC Models}

The MOSCED model (Lazzaroni et al., 2005), generates infinite dilution activity coefficients. In order to obtain a noninfinite dilution activity coefficient, another activity coefficient model is required. The Van Laar, Wilson, and NRTL models were each combined with the MOSCED model to evaluate which would give the best prediction to known experimental data. The next solubility model considered is the UNIFAC model (Anderson and Prausnitz, 1978). The UNIFAC model predicts activity coefficients based on group contributions. The MOSCED and UNIFAC models predicted equilibrium profiles for acetaminophen in acetone and water are shown in Figure 1.

The MOSCED models all give very poor solubility predictions. They all greatly underestimate the solubility. The NRTL and Wilson models give better estimates to the shape of the solubility curve than the Van Laar model does. The UNIFAC model is the worst of the models both greatly overestimating the solubility and weakly representing the shape of the curve. 


\subsection{NRTL-SAC, Jouyban-Acree, and Empirical Models}

The next solubility model considered is the NRTL-SAC model (Chen et al., 2004, 2006). The NRTL-SAC model is a NRTL activity coefficient model that has been modified using segment theory (Chen et al., 2004, 2006). The last predictive solubility model considered is the Jouyban-Acree model (Jouyban et al., 2006).

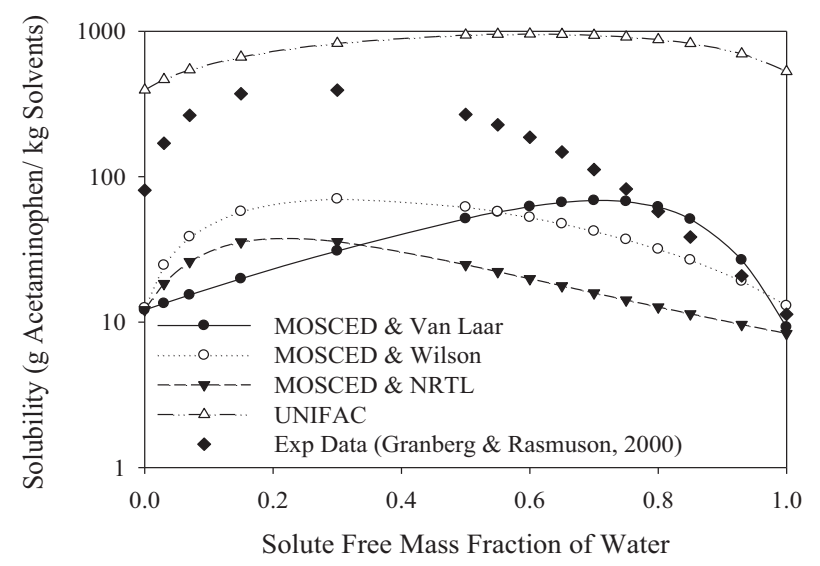

Figure 1: MOSCED \& UNIFAC Solubility Predictions.

The Jouyban-Acree model is a semi-empirical model developed to predict the solubility of pharmaceuticals in organic solutions. This model requires the solubilities of both pure components in a binary solute-solvent system, and predicts the solubility of a solute in a solvent mixture. The last solubility model considered is an empirical model generated from data from Granberg and Rasmuson (2000) by Zhou et al. (2006).

$$
\begin{aligned}
C^{*}= & -5.01902 \times 10^{-12} w^{6}+1.69767 \times 10^{-9} w^{5} \\
& -2.46765 \times 10^{-7} w^{4}+2.19262 \times 10^{-5} w^{3} \\
& -1.27018 \times 10^{-3} w^{2}+3.42614 \times 10^{-2} w \\
& +7.96086 \times 10^{-2}
\end{aligned}
$$

Where $C^{*}$ is the equilibrium concentration $(\mathrm{kg}$ acetaminophen $/ \mathrm{kg}$ solvents), and $w$ is the solute free mass percent of water. The NRTL-SAC, Jouyban-Acree, and empirical model predicted solubilities are plotted in Figure 2.

The NRTL-SAC and Jouyban-Acree solubility models both predict the equilibrium solubility much better than the MOSCED or UNIFAC models did. The empirical model fits the data very well and will be considered as the standard solubility model for benchmarking. Since the UNIFAC and MOSCED models gave such poor solubility predictions, only the NRTL-SAC and Jouyban-Acree models will be compared against the empirical model in the optimization sensitivity study in the subsequent sections.

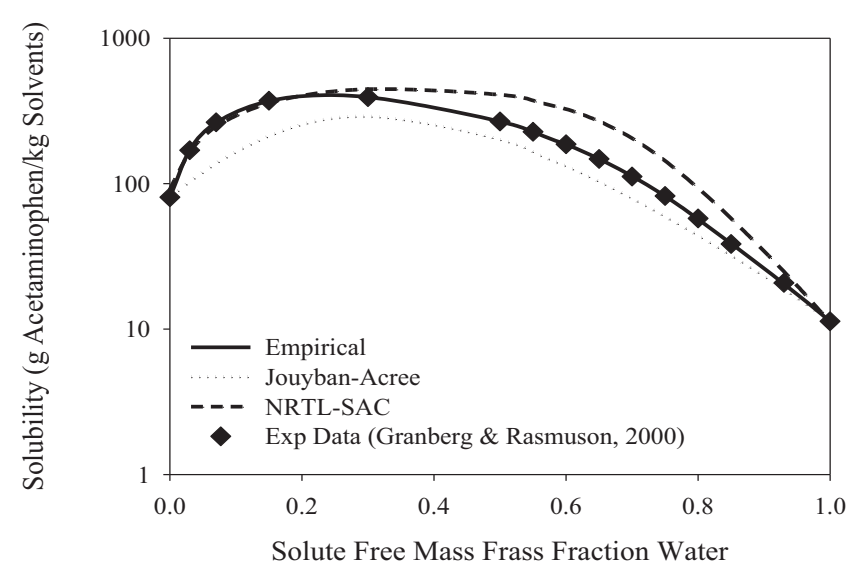

Figure 2: NRTL-SAC and Jouyban-Acree Solubility Predictions.

\section{CRYSTALLIZATION MODEL}

In order to evaluate the effect of the solubility model on the predicted optimal trajectories, a crystallization model is required.

\subsection{Population Balance}

The population balance for a crystallization system having size-independent crystal growth and without attrition or agglomeration is defined in (2).

$\frac{\partial n(L, t)}{\partial t}+\frac{n(L, t)}{V} \frac{d V}{d t}+G \frac{\partial n(L, t)}{\partial L}-B=0$

Where $n(L, t)$ is the crystal density (\# of particles $/ \mathrm{m}^{3}$ ), $V$ is the volume $\left(\mathrm{m}^{3}\right), G$ is the growth rate $(\mathrm{m} / \mathrm{s})$, and $B$ is the nucleation rate (\# of particles/ $\mathrm{s} \mathrm{m}^{3}$ ). The population balance was solved by discretization using backward finite differences. The discretization consisted of 250 geometrically spaced intervals from 0.5-1000 microns.

\subsection{Crystallization Kinetics}

The antisolvent crystallization kinetics for acetaminophen in acetone with water as the antisolvent were taken from Zhou et al (2006). The authors developed their own kinetic rates (3-6), from previous crystallization data performed by Granberg et al. (1999, 2001).

$$
\begin{aligned}
N= & 8.56080 \times 10^{8} \times \\
& \exp \left\{-1.22850 \times 10^{-3} \frac{\ln ^{3}\left(\frac{\rho_{c}}{C^{*} \rho_{s}}\right)}{\ln ^{2}\left(\frac{C}{C^{*}}\right)}\right\} \\
G= & k_{g}\left(C-C^{*}\right)^{g} \\
k_{g}= & 4.01067 \times 10^{-8} w^{2}-1.76198 \times 10^{-6} w \\
& +5.78135 \times 10^{-5} \\
g= & -4.22536 \times 10^{-3} w+1.77428
\end{aligned}
$$


Where $N$ is the nucleation rate (no. of particles $/ \mathrm{m}^{3}$ ), $\rho_{c}$ is the crystal density of acetaminophen $\left(\mathrm{kg} / \mathrm{m}^{3}\right), C^{*}$ is the equilibrium concentration defined previously, $C$ is the solution concentration ( $\mathrm{kg}$ acetaminophen $/ \mathrm{kg}$ solvents), $\rho_{s}$ is the density of the solution $\left(\mathrm{kg} / \mathrm{m}^{3}\right), G$ is the crystal growth rate $(\mathrm{m} / \mathrm{s})$, and $w$ is the solute free mass percent of antisolvent (water) in the solution. Also, the growth kinetics is only valid for solute free water mass percents greater than $30 \%$.

\section{OPTIMIZATION}

The first optimization objective $(\mathrm{O}-1)$ was to create a final volume mean crystal size $\left(\mathrm{D}_{43}\right)$ of 200 microns, and jointly minimize the total amount of nucleation by minimizing the zeroth moment. The optimization constraints were to end with a solute free antisolvent mass percent of water of $88 \%$, and the mass flow rate of water could range between 0 and $400 \mathrm{~g} / \mathrm{min}$. The duration of the experiment was fixed at 4200 $\mathrm{s}$. The control interval was discretized into 10 fixed $360 \mathrm{~s}$ intervals where the antisolvent flow rate could be adjusted in a piecewise constant manner. The final $600 \mathrm{~s}$ had a fixed antisolvent flow rate of zero. This was done to ensure that all remaining supersaturation is consumed at the end of the run. The optimizations were implemented using the gPROMS package (Process System Enterprise, UK) using the gOPT entity. The objective function used is defined in (7) subject to initial conditions in (8).

$$
\begin{aligned}
& O B J=\max _{43}\left\{\begin{array}{c}
D_{43} \leq 200 \mu \mathrm{m} \\
w_{f}=88 \% \\
\min \mu_{0} \\
0 \leq \frac{d W}{d t} \leq 400 \mathrm{~g} / \mathrm{min} \text { Water }
\end{array}\right. \\
& T=16^{\circ} \mathrm{C} \quad w_{i}=40 \% \quad n_{i}(L, 0)=0 \quad C_{i}=C_{i}^{*}
\end{aligned}
$$

This optimization was carried out using the crystallization model in Section 3 separately with each of the empirical, Jouyban-Acree, and NRTL-SAC solubility models. The MOSCED and UNIFAC models were not considered because when those models where incorporated into the crystallization model they did not predict any crystallization phenomena.

\subsection{Optimal Antisolvent Feed Profiles for O-1.}

Each solubility model resulted in an optimal profile (Figure 3).. The empirical and Jouyban-Acree models generated similar optimal profiles (denoted Profile A.1 and Profile B.1 respectively) with a small initial flow rate at the beginning of the experiment, moderate flow rate in the middle, and higher flow rate at the end. In contrast, the NRTL-SAC model calculates an optimal profile (denoted Profile C.1) that has a moderate initial flow rate followed by a high flow rate in the middle, and no flow at the end.

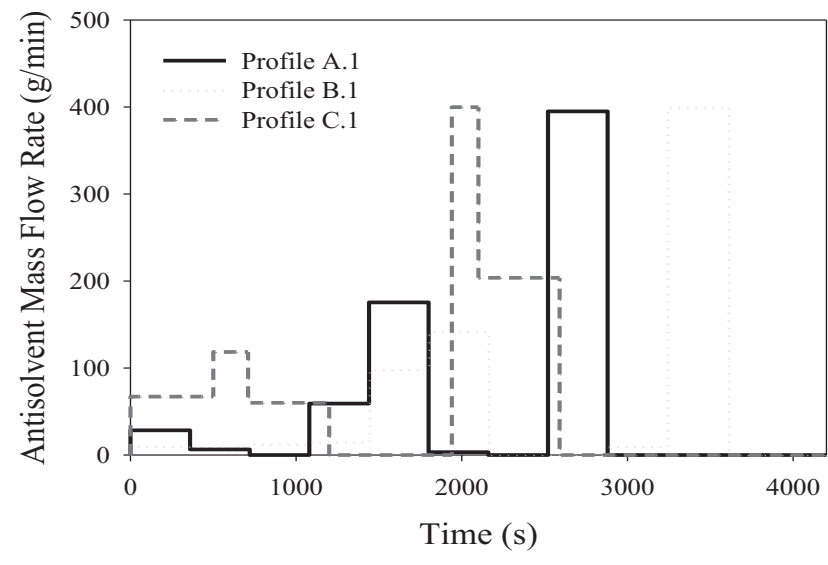

Figure 3: Optimal antisolvent feed profiles for O-1.

The second optimization objective $(\mathrm{O}-2)$ was to create a larger final volume mean size $\left(\mathrm{D}_{43}\right)$ of 400 microns while again minimizing the total amount of nucleation by minimizing the zeroth moment. The objective function formulation for $\mathrm{O}-2$ was the same as for O-1 with the exception that $\mathrm{D}_{43}$ now cannot be greater than 400 microns.

\subsection{Optimal Antisolvent Feed Profiles for $\mathrm{O}-2$.}

Each solubility model resulted in a new optimal profile for O2 (Figure 4). The empirical and Jouyban-Acree models again generated similar optimal profiles (denoted Profile A.2 and Profile B.2 respectively) with a small initial flow rate at the beginning of the experiment, a high flow rate in the middle for A.2, and a high flow rate at the end for B.2. In contrast, the NRTL-SAC model calculates an optimal profile (denoted Profile C.2) that has a moderate initial flow rate followed by a low flow rate in the middle, and a moderate flow rate at the end.

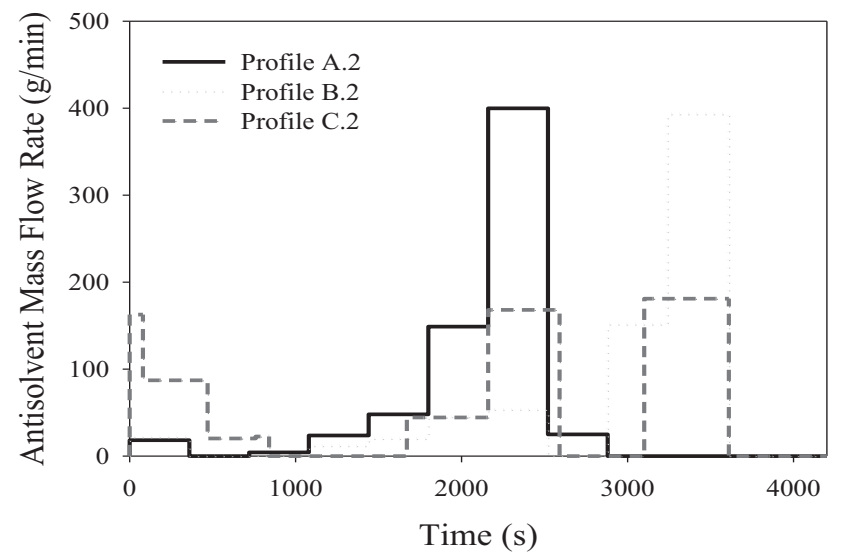

Figure 4: Optimal antisolvent feed profiles for O-2.

\section{OPTIMIZATION SENSITIVITY ANALYSIS}

The crystallization model was executed for each generated optimal feed profile (A.1-C.2) using the empirical solubility model. The empirical model is used as the benchmark since it 
showed very close agreement to experimental solubility data. This should predict what these optimal profiles would actually produce in a real crystallizer. Results are shown in the next sections.

\subsection{Optimal Profiles for O-1 Evaluation}

When the optimal profiles are implemented into the empirical solubility model there are several observed differences in the simulated supersaturation profiles (Figure 5) under Profiles A.1, B.1, and C.1. The NRTL-SAC optimal profile (C.1) causes the supersaturation to peak earlier than the other two models, while the supersaturation caused by the JouybanAcree profile (B.1) is shown to be similar in shape to the empirical profile (A.1) but with a delay. Next, the effect on the volume mean size growth is shown in Figure 6.

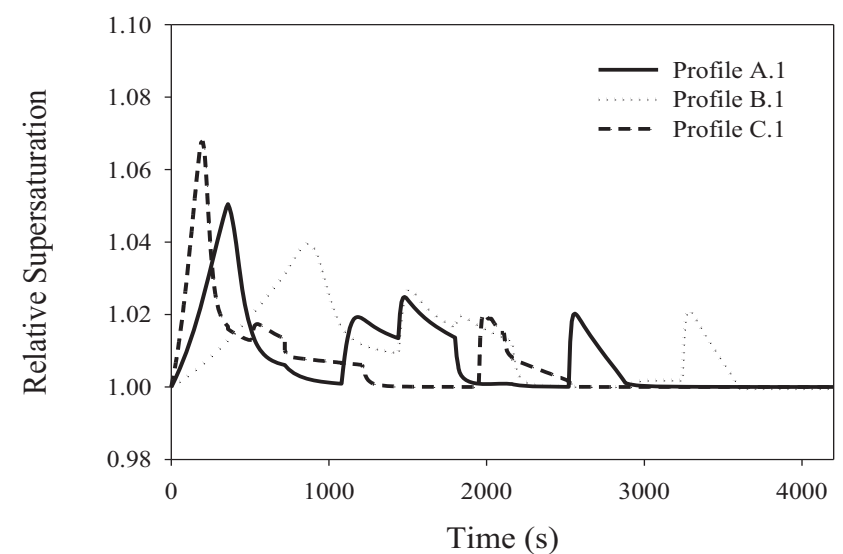

Figure 5: Relative supersaturation profiles for each optimal antisolvent feed profile for O-1.

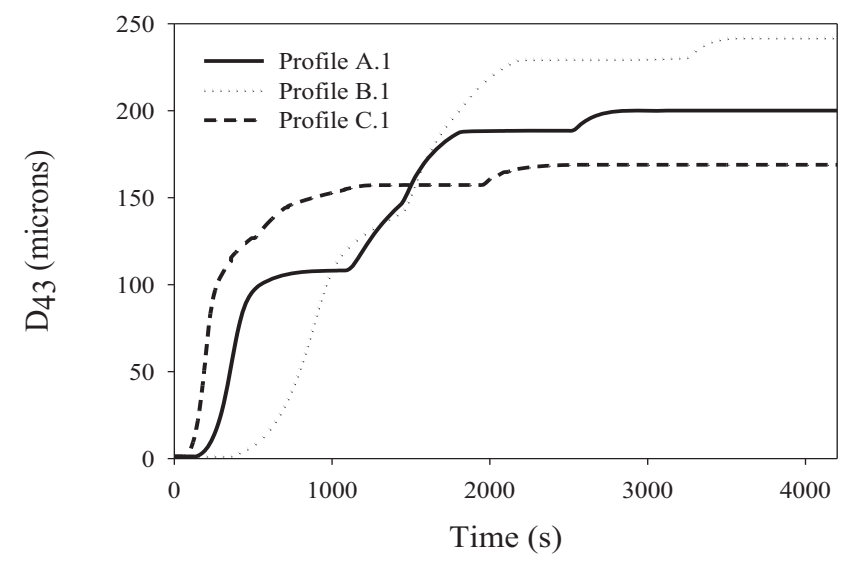

Figure 6: Volume mean size for each optimal antisolvent feed profile for O-1.

Each volume mean size profile can be explained by its corresponding supersaturation curve. Whenever the supersaturation increases there is a corresponding increase in the volume mean size. The NRTL-SAC optimal profile's (C.1) supersaturation profile only has one large early supersaturation peak which causes the first primary increase in crystal size, and a second peak which causes a small increase in crystal size. The empirical optimal profile's (A.1) generated supersaturation profile has four peaks which cause four increases in crystal size. Likewise the Jouyban-Acree optimal profile (B.1) causes the supersaturation profile to have four increases in $\mathrm{D}_{43}$. Using the empirical solubility model, the empirical optimal profile (A.1) satisfies its objective of 200 microns, the Jouyban-Acree optimal profile (B.1) is higher at 242 microns, and the NRTL-SAC optimal profile (C.1) is lower at 169 microns. Both predictive models optimal profiles did not meet the optimization objective but are within $20 \%$ of the desired value.

Figure 7 shows the volume percent CSD for each optimal profile. All three optimal profiles give similar distributions with the NRTL-SAC optimal profile (C.1) distribution having a lower mean size than the others, and the Jouyban-Acree optimal profile (B.1) distribution having a larger mean size. All three optimal profiles generated distributions with similar width.

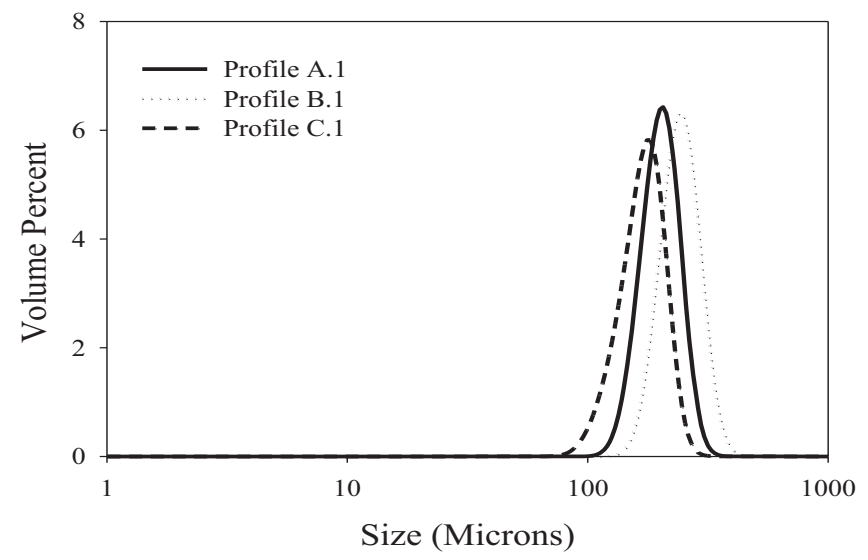

Figure 7: Volume percent CSD for each optimal antisolvent feed profile for $\mathrm{O}-1$.

For this objective function (O-1) only the empirical model's optimal profile (A.1) was able to satisfy the objective to create a volume mean size of 200 microns, but the predictive models' profiles (B.1 \& C.1) were able to be within $20 \%$ of the desired value. Also, all three profiles were successfully able to suppress nucleation to produce unimodal profiles.

\subsection{Optimal Profiles for O-2 Evaluation}

The next objective function considered is the 400 volume mean size objective function $(\mathrm{O}-2)$. As seen in Figure 8 the generated supersaturation profiles follow the same trend as for the first objective function (O-1). The NRTL-SAC optimal profile (C.2) generates a supersaturation profile that is nearly identical to the supersaturation profile that C.1 generated for O-1. The empirical optimal profile (A.2) generates a supersaturation amount that is above 1.02 from 500 to 2500 s. The Jouyban-Acree optimal profile (B.2) generates a supersaturation peak that is similar to (A.2) but not as high of a supersaturation amount. 


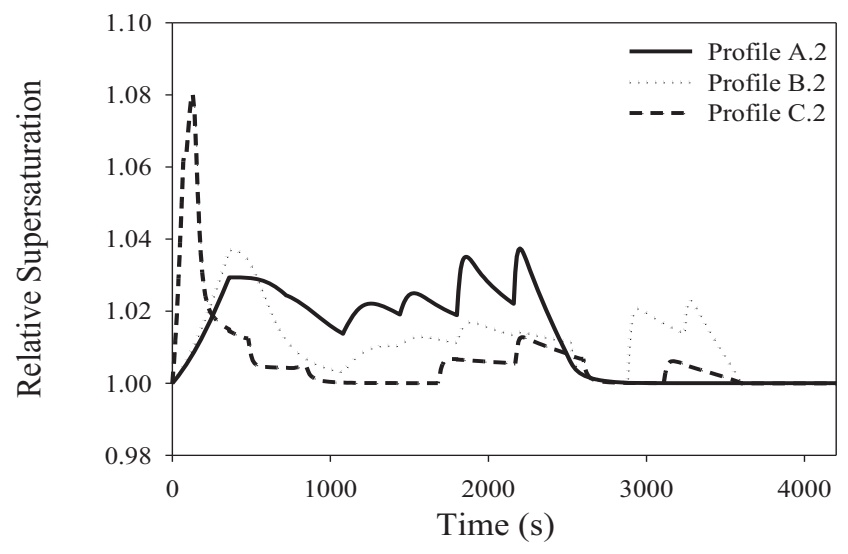

Figure 8: Relative supersaturation profiles for each optimal antisolvent feed profile for O-2.

The Jouyban-Acree (B.2) and NRTL-SAC (C.2) optimal profiles both generated a much smaller mean size because they did not generate the required supersaturation. The Jouyban-Acree optimal profile (B.2) generated a volume mean size of 271 microns and the NRTL-SAC optimal profile (C.2) generated a volume mean size of 162 microns. Both predictive solubility models' optimal profiles do not satisfy O-2 as well as they satisfied O-1.

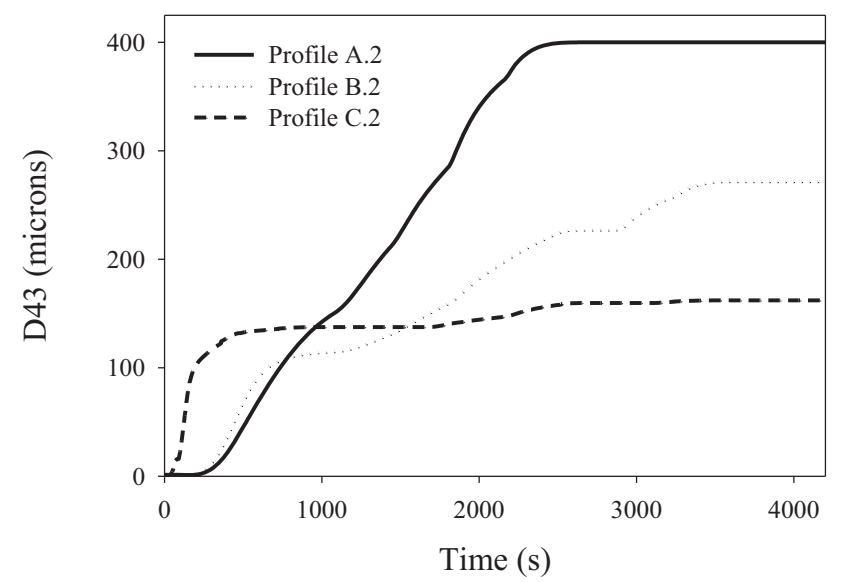

Figure 9: Volume mean size for each optimal antisolvent feed profile for O-2.

Figure 10 shows the volume percent CSD for each optimal profile for $\mathrm{O}-2$. For this case there is a larger difference between the three profiles. Clearly, the Jouyban-Acree (B.2) and NRTL-SAC (C.2) optimal profiles did not satisfy the optimization objective. Also, the distribution width had more variation between the three profiles. The empirical profile (A.2) had the lowest distribution width, followed by the Jouyban-Acree (B.2) and the NRTL-SAC (C.2) model had the largest distribution width.

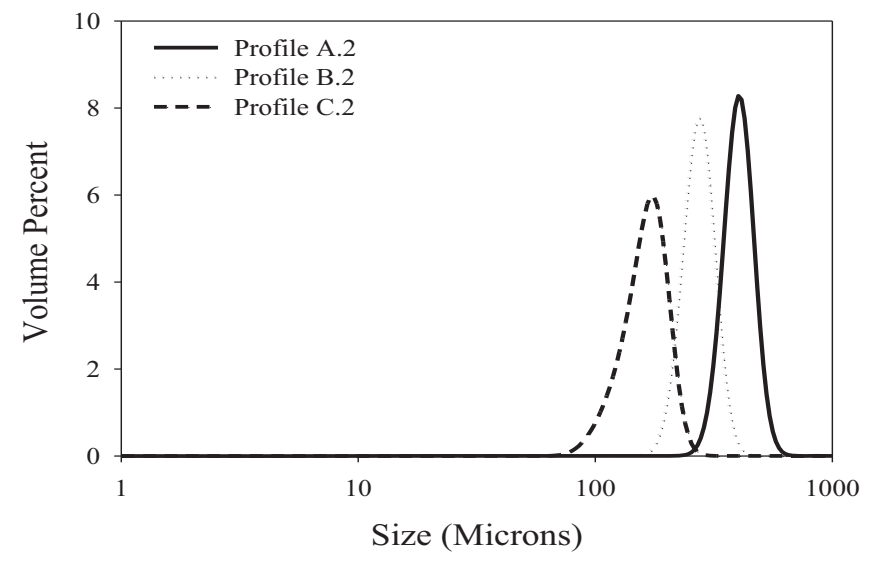

Figure 10: Volume percent CSD for each optimal antisolvent feed profile for $\mathrm{O}-2$.

Just as for the first case (O-1) only the empirical model's optimal profile (A.2) was able to satisfy the objective (O-2) to create a volume mean size of 400 microns. Both predictive model profiles (B.2 \& C.2) produced a much smaller mean size. The Jouyban-Acree profile (B.2) produced particles $32 \%$ smaller, and the NRTL-SAC profile (C.2) produced particles $60 \%$ smaller. Even though they did not produce the proper volume mean size, all three profiles were successfully able to suppress nucleation to produce unimodal profiles.

\subsection{Optimization Evaluation}

The reason why the optimal flow rates are similar for both the empirical and Jouyban-Acree model is that the slopes of both solubility curves are very similar. Since the slope of the solubility curve is what dictates the supersaturation profile, it would be expected to give similar supersaturation profiles. The NRTL-SAC model has a different slope in its solubility profile which causes the larger deviation in these reported results. In order for a predictive solubility model to produce predictive optimal profiles it must be accurate both quantitatively and qualitatively.

Table 1: Final volume mean crystal size derived from each optimal profile.

\begin{tabular}{lcccc}
\hline & \multicolumn{4}{c}{ Final Volume Mean Size \& Percent Error } \\
\hline $\begin{array}{l}\text { Optimal } \\
\text { Feed }\end{array}$ & $\begin{array}{c}\text { O-1 } \\
\text { Profile }\end{array}$ & $\begin{array}{c}\text { Percent } \\
\text { Error }\end{array}$ & $\begin{array}{c}\text { O-2 } \\
(400)\end{array}$ & $\begin{array}{c}\text { Prediction } \\
\text { Percent } \\
\text { Error }\end{array}$ \\
\hline $\begin{array}{l}\text { Empirical } \\
\text { Jouyban- }\end{array}$ & 200 & 0 & 400 & 0 \\
$\begin{array}{l}\text { Acree } \\
\text { NRTL- }\end{array}$ & 242 & $21 \%$ & 271 & $-32 \%$ \\
SAC & 169 & $-16 \%$ & 162 & $-60 \%$ \\
\hline
\end{tabular}

Only the optimal profiles (A.1, A.2) generated from the empirical solubility model were able to satisfy both optimization objectives. When other optimal profiles were used the final volume mean size was as much as $60 \%$ under predicted and $21 \%$ over predicted when implemented into the 
empirical solubility model. The deviation from the objective criteria increased as the volume mean size increased.

\section{CONCLUSION}

The effect of several solubility models were evaluated on the predicted optimal antisolvent feed profiles. The solubility model did have an effect on the optimal profile, and generated a unique optimal antisolvent feed profile. The use of the predictive solubility models' optimal profiles in the empirical solubility model did not satisfy the original objective function. The use of an incorrect solubility model will create a sub-optimal antisolvent feed profile that will not satisfy its intended crystallization optimization objective in a real system. This underpins the significance of the solubility profile in crystallisation optimizations work.

\section{REFERENCES}

Anderson T.F., Prautsnitz J.M. (1978), Application of the UNIQUAC Equation to Calculation of Multicomponent Phase Equilibria 2: Liquid-Liquid Equlibria, Industrial \& Engineering Chemistry Process Design and Development, 17-4, 561-567

Braatz R.D. (2002), Advanced Control of Crystallization Processes, Annual Reviews in Control, 26, 87-99.

Chen C.C., Crafts P.A. (2006), Correlation and Prediction of Drug Molecule Solubility in Mixed Solvent Systems with the Nonrandom Two-Liquid Segment Activity Coefficient (NRTL-SAC) Model, Industrial \& Engineering Chemistry Research, 45, 4816-4824.

Chen C.C., Song S. (2004), Solubility Modelling with a Nonrandom Two-Liquid Segment Activity Coefficient Model, Industrial \& Engineering Chemistry Research, 43, 8354-8362.

Granberg R. A., Bloch D. G., Rasmuson A. C. (1999), Crystallization of Paracetamol in Acetone-Water Mixtures, Journal of Crystal Growth, 198/199, 1287-1293.

Granberg R. A., Ducreux C., Gracin S., Rasmuson A. C. (2001), Primary Nucleation of Paracetamol in Acetone-Water Mixtures, Chemical Engineering Science, 56, 2305-2313.

Granberg R.A., Rasmuson A.C. (2000), Solubility of Paracetamol in Binary and Ternary Mixtures of Water, Journal of Chemical \& Engineering Data, 45, 478-483.

Hulbert H.M., Katz S. (1964), Some Problems in Particle Technology, Chemical Engineering Science, 19, 555.
Jouyban A., Chan H.K., Chew N.Y.K., Khoubnasabjafari M., Acree, Jr. W.E. (2006), Solubility Prediction of Paracetamol in Binary and Ternary Solvent Mixtures Using Jouyban-Acree Model, Chemical and Pharmaceutical Bulletin, 54-4, 428-431.

Lazzaroni M., Bush D., Eckert C. (2005), Revision of MOSCED Parameters and Extension to Solid Solubility Calculations, Industrial \& Engineering Chemistry Research, 44, 4075-4083.

Lindenberg C., Krattli M., Cornel J., Mazzotti M., Brozio J. (2009), Design and Optimization of a Combined Cooling/Antisolvent Process, Crystal Growth \& Design, 9:2, 1124-1136.

Nowee S.M., Abbas A., Romagnoli J.A. (2008), ModelBased Optimal Strategies for Controlling Particle Size in Antisolvent Crystallization Operations, Crystal Growth \& Design, 8:8, 2698-2706.

Ramkrishna D. (1985), The Status of Population Balances, Reviews in Chemical Engineering, 3:1, 49-95.

Randolph A.D., Larson M.A. (1988), Theory of Particulate Processes (2nd ed.), Academic Press, San Diego, CA.

Sheikhzadeh M., Trivkovic M., Rohani S. (2008), Real-time optimal control of an anti-solvent isothermal semibatch crystallization process, Chemical Engineering Science, 63, 829-839.

Zhou G.X., Fujiwara M., Woo X.Y., Rusli E., Tung H.H., Starbuck C., Davidson O., Ge Z., Braatz R.D. (2006), Direct Design of Pharmaceutical Antisolvent Crystallization through Concentration Control, Crystal Growth and Design, 6-4, 892-898. 